\title{
Substantiation of the arrangement and parameters of the loosening compacting discs of tillage rollers with a bionic approach
}

\author{
$L F$ Babitsky $^{1}, I V$ Sobolevsky $^{1,2, *}$, and $Y N$ Ismailov $^{1}$ \\ ${ }^{1}$ V. I. Vernadsky Crimean Federal University, 4, Vernadskogo avenue, Simferopol, Republic of \\ Crimea, 295007, Russia \\ ${ }^{2}$ Research Institute of Agriculture of Crimea, 150, Kievskaya Street, Simferopol, Republic of Crimea, \\ 295493, Russia
}

\begin{abstract}
The article presents the methods and results of bionic modeling in agricultural mechanics, which made it possible to substantiate the arrangement and parameters of the working bodies of the loosening compacting discs of tillage rollers adapted to the soil environment using the regularities of the arrangement of thorns on wide rings of the tail in the biological prototype of the girdle tail (Cordylidae). Based on the principle of multi-contact action of the teeth and toothed plates of the roller discs on the soil layer, the coefficient of the arrangement of the discs on the roller is equal to $0.22 \ldots 0.24$, as well as the number of toothed plates and teeth on the working surface of the loosening compacting disc of the roller, which is in the range of $6 \ldots 12$, which is consistent with the arrangement of spines along the circumference of the wide rings on the tail of the girdle. The results of experimental studies, confirming the decrease in the traction resistance of the proposed working bodies of the loosening compacting discs of tillage rollers for surface tillage are presented.
\end{abstract}

\section{Introduction}

To increase yields with resource-saving technologies for cultivating grain crops, it is important to improve the quality of soil preparation. Its purpose is to form the structure of the soil and the density of the sowing layer that meet the agrotechnical requirements, where the working bodies of tillage rollers are applicable [1].

However, as the analysis of existing designs of serial tillage rollers shows, the available theoretical developments for determining their parameters were mainly aimed at studying the deformation of the compacted soil layer without substantiating the shape of the working bodies of the teeth and toothed plates, taking into account their spacing, affecting the closure of deformation zones cultivated soil layer. The solution of the tasks posed to substantiate the shapes of the working bodies of the loosening compacting discs of tillage rollers is proposed on the basis of the application of the mechanical-bionic approach, which

\footnotetext{
*Corresponding author: sobolevskii-ivan@mail.ru
} 
allows analytically to find the spacing, to describe the geometric shape of the teeth and toothed plates.

The purpose of the research is the development of theoretical prerequisites for the bionic substantiation of the parameters of the working bodies of the loosening compacting discs of tillage rollers for surface tillage.

\section{Materials and methods}

To consider the investigated object in the biological system "soil-plant-atmosphere", modeling in bionics based on the biostemic approach is used, which is the main research method. The objects under study were: the natural model of the biological prototype of the girdle-tail (Cordylidae) and the physical model of the working bodies of the loosening compacting discs of tillage rollers for their joint comparative studies, taking into account living systems and machines.

\section{Results}

The main tasks of soil tillage rollers are compaction, breaking up clods and leveling the soil, as well as regulating the depth of tillage and finally shaping the structure of the seedbed. In the existing designs of modern tillage rollers for resource-saving technologies, the most widespread are spur, toothed and wedge-shaped working bodies. A feature of the designs of these types of rollers are working bodies in the form of disks with lateral projections - spurs, or central projections on the working part of the disks in the form of teeth and wedges.

Accordingly, each of these elements fulfills its task, while the main disadvantage is that a separate tillage roller is completed for them. This leads to limited possibilities of using rollers for certain types of soil. New types of maximally zoned soil-cultivating rollers are needed, which will provide a significant increase in labor productivity by performing several operations in one pass and will save fuel and energy resources. The creation of such tillage rollers should be based on scientific research, considering a special biological system "soil environment - rollers" taking into account direct and feedback [1-4].

Exploratory studies have shown that special attention should be paid to the biological structural elements of the biological prototype of burrowing spines in girdle tails (Cordylidae) [5-6]. Spines - bone plates located on the tail in the form of wide rings (belts) are shown in fig. 1 (a). Due to its structure, girdle tails are well adapted to rocky and arid regions. Due to the bony plates, the girdle tails form well passages in rocky ground. At the same time, a special task is performed by well-developed five-toed limbs and a tail, on which 6 .. 8 wide rings are located. Each ring in cross-section, shown in fig. 1 (b), consists of a certain number of studs located around its circumference with a certain pitch $S$ depending on the number of studs of width $b$. Since the loosening discs of soil tillage rollers contain teeth and toothed plates located with a certain pitch $S$, then for the analytical substantiation of the pitch of the arrangement, digging spikes at the tails can be used as their bionic prototype $[1,6]$. 


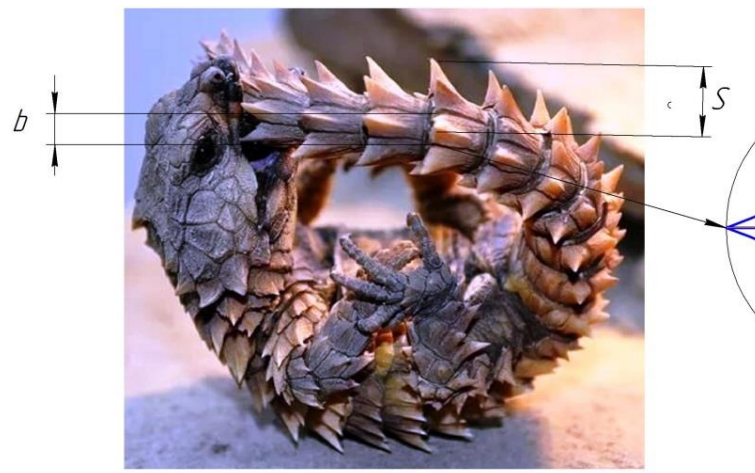

(a)

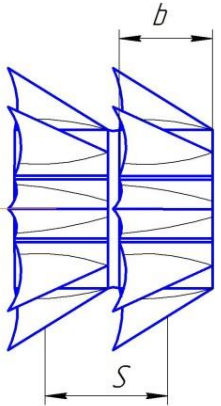

scale 12

(b)

Fig. 1. Approximation of burrowing thorns at girdle tails (Cordylidae): a - general view of the girdle (Cordylidae); $\mathrm{b}$ - cross-sectional projection of wide girdle tail rings.

Based on the principle of the multi-contact action of the teeth and toothed plates of the roller discs on the soil layer, the interaction of the roller with the soil, shown in fig. 2, can be described by the basic equation of the multi-contact problem [1, 4]:

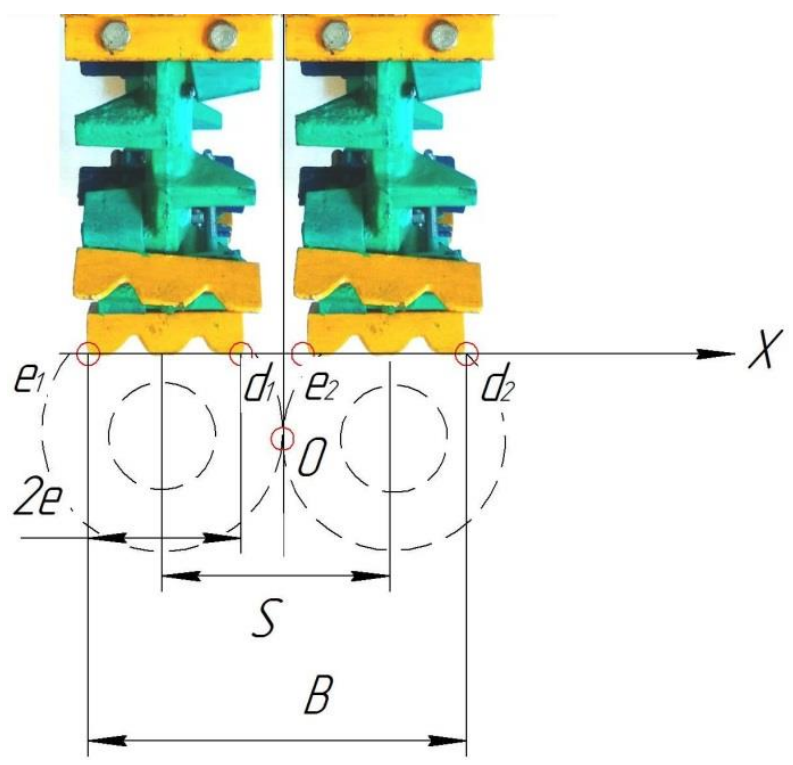

Fig. 2. Layout of loosening compacting discs with toothed plates on the roller axis.

$$
\sum_{m=1}^{n} \int_{e_{m}}^{d_{m}} F(t) \ln \frac{1}{|t-x|} d t=\frac{f(x)}{v}
$$

where $F(t)$ is the function of the force action of the disks on the soil within the interval $e_{m} d_{m}$

$f(x)$ is the function describing the shape of the surface of the roller disc within an interval $e_{m} d_{m}$

$\boldsymbol{V}$ is the deformation index of soil [1]; 
$\mathcal{X}$ is the current coordinate.

The pressure distribution over one of the contact areas $e_{m} d_{m}$ of the loosening compacting discs with the toothed plates based on the solution to equation (1) is determined by the expression:

$$
F(x)=\frac{F}{\pi \sqrt{e^{2}-x^{2}}}
$$

where $F$ is the force created by one disc of the roller;

$e$ is the half-width of the contact area.

To crush the soil with the toothed discs of the tillage roller, the minimum pressure at the contact area must exceed the temporary resistance of the soil to destruction. Taking $F(0)$ equal to $F p$ from expression (2), we find the force required to cut the soil with a toothed disc plate:

$$
F_{p}=\pi \cdot e \cdot F_{d}
$$

considering that

$$
F_{d}=\frac{2}{\pi^{2} \cdot \gamma}
$$

get

$$
F_{p}=\frac{2 e^{2}}{\pi \gamma}
$$

For cutting the soil with toothed plates of the entire loosening compact disc roller, the force created by it is determined by the expression:

$$
F=F_{p} \cdot m
$$

where $m$ is the number of disks.

If the tillage is carried out with a loosening compacting disc tillage roller with a working width of $B$ and the number of discs with toothed plates of width $2 e$ and a pitch $S$, as shown in fig. 2, then expressing the width of the roller in terms of the basic geometric parameters of the discs with toothed plates, it is possible to determine their number:

$$
m=\frac{B+S-2 e}{S} .
$$

Denoting the ratio of the half-width e of the toothed plates to the pitch $S$ through the coefficient of the arrangement of the disks $k$, we obtain:

$$
m=\frac{B+S \cdot(1-2 k)}{S}
$$




$$
S=\frac{B}{m-(1-2 k)}
$$

Substituting the values $m$ from expression (6) $F_{p}$ and from expression (3) into equation (4), we obtain:

$$
F=\frac{2 e^{2} \cdot B \cdot k}{\pi \cdot \gamma} \cdot\left[1+\frac{(1-2 k)}{m-(1-2 k)}\right]
$$

The dependence of $F$ on $k$ according to equation (7) at constant $m$ is hyperbolic. With an increase in the number of disks $m$ on the roller, the convexity of the hyperbola decreases and the function $F(k)$ approaches a linear dependence. Therefore, the maximum reduction in the force of the loosening disc soil tillage roller, in comparison with a solid roller, will be ensured when $\mathrm{k}$ is the corresponding extreme value of the function.

Examining function (7) for the extremum by the Lagrange finite-increment theorem, we finally obtain $k_{\text {opt }}$, determined by the solution of the quadratic equation:

$$
4 k_{o p t}^{2}-4 k_{o p t}+4 m k_{o p t}-m+1=0 .
$$

The ratio of the arrangement of the disks on the roller is determined by solving the equation (8):

$$
k=\frac{\sqrt{m^{2}-m}-m+1}{2} .
$$

Solution (9) of equation (8) in the form of a graph of the dependence $k=f(m)$ is shown in fig. 3 .

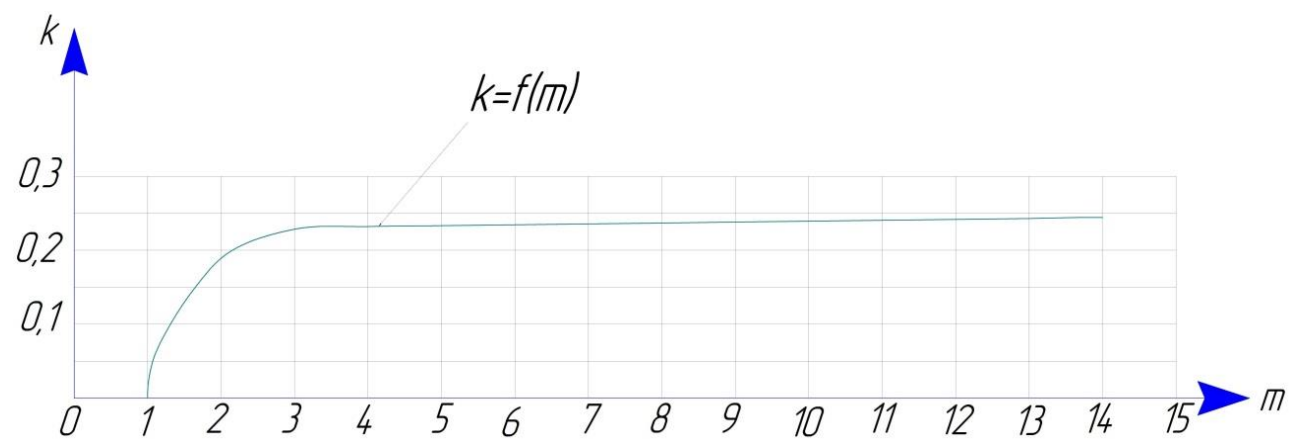

Fig. 3. Graphical dependence of the coefficient of arrangement of $k$ discs on the number $m$ of discs on the roller axis.

As can be seen from fig. 3, with an increase in the number of discs on the roller from 6 to 12 and more, the value of the location coefficient changes insignificantly and is in the range of $0.22 \ldots 0.24$. Consequently, the optimal value of the coefficient of the arrangement of the discs on the tillage roller can be considered $0.22 \ldots 0.24$, which is consistent with the arrangement of the studs along the circumference of the wide rings on the tail of the girdle tail [7-8]. 
The substantiated value of the coefficient of the arrangement of the discs of the tillage roller is practically equal to the values of the coefficient of the arrangement of the spikes on the wide rings of the tail of the biological prototype of the girdle tail $(0.21 \ldots 0.24)$, shown in fig. 1 .

When driving and acting on the soil, the distance traveled by the loosening compacting disc of the tillage roller in one revolution is determined by the expression:

$$
L=2 \cdot \pi \cdot r,
$$

where $r$ is the radius of the roller disk, which is in the range of $200 \ldots 250 \mathrm{~mm}$.

If the number of toothed plates and teeth is fixed on the roller disk $N$, then the distance between the cone-shaped notches made by them in the soil is determined by the expression:

$$
l=\frac{L}{N}=\frac{2 \cdot \pi \cdot r}{N} .
$$

Based on the analysis of prospecting studies by the distance $l_{r}$ between the spikes along the circumference of the wide rings located on the tail of the girdle shown in fig. 4 (a), approximating the roller disc circumference to the working surface from expression (11), we can determine the required number of toothed plates and teeth on the disc rim skating rink by expression:

$$
N=\frac{2 \cdot \pi \cdot r}{l_{r}}
$$
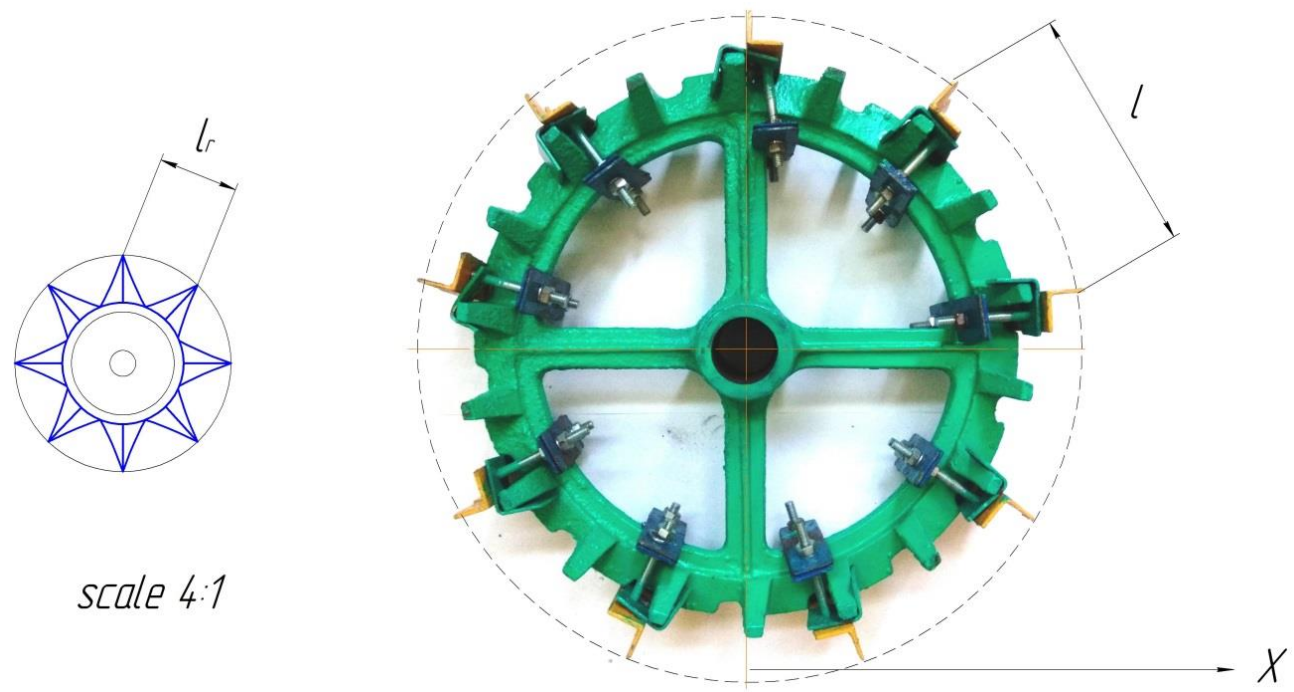

Fig. 4. Approximation of the distance between: a - thorns along the circumference of wide rings located on the tail of the girdle (Cordylidae); $b$ - toothed plates located on the working surface along the entire circumference of the roller discs.

An experimental model of a tillage roller with loosening compacting discs (RF patent No. 199408) [9], shown in fig. 5 (a), contains axis 1, on which discs 2 with toothed plates 3 and teeth 4 are installed. 


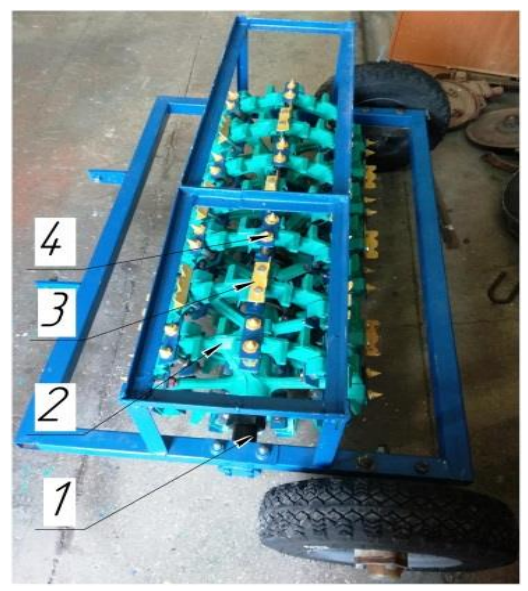

(a)

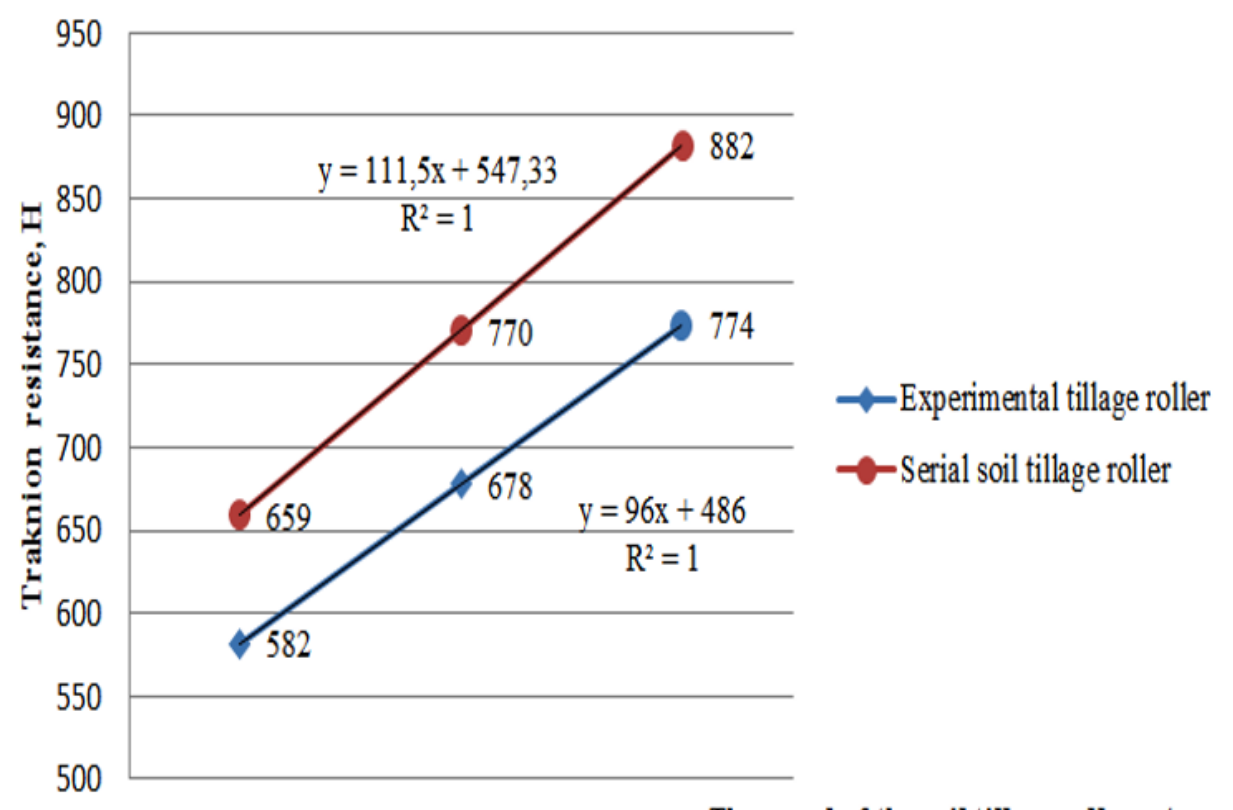

123 The speed of the soil tillage roller, $\mathrm{M} / \mathrm{s}$

(b)

Fig. 5. Tests of the experimental model of the roller: a - general view of the tillage roller with loosening compacting discs; $\mathrm{b}$ - graphical dependence of the traction resistance of a soil tillage roller with loosening compacting discs on the speed.

Experimental verification of the traction resistance of the tillage roller with loosening compacting discs, shown in fig. 5 (a), in comparison with the serial model 3 RSR-6, when carrying out experimental passes in the soil channel, confirmed the expediency of its use [10]. When testing in a soil channel, soil moisture was $15 \ldots 17 \%$, soil hardness $39.8 \ldots 52.4$ $\mathrm{N} / \mathrm{cm}^{2}$, deformation index $2.6 \cdot 10^{-7} \ldots .3 .5 \cdot 10^{-7} \mathrm{~m}^{2} / \mathrm{N}$, soil type - southern black earth [1114].

Fig. 5 (b) shows the graphical dependences of the traction resistance of the experimental model of the soil tillage roller with loosening discs on the speed of movement in comparison with the serial model 3 RSR - 6 [15]. 
An experimental model of a soil tillage roller with loosening compacting discs reduces traction resistance by $12 \ldots 14 \%$, in comparison with the serial model 3 RSR - 6 . This improves the efficiency of crumbling soil clods and crop residues with toothed plates and tines, while ensuring simultaneous local consolidation across the entire working width of the soil tillage roller.

\section{Conclusion}

Based on the analysis of the structural features and location of burrowing thorns in the biological prototype of the girdle-tail (Cordylidae), a model of a soil-cultivating roller with loosening compacting discs (RF patent No. 199408) has been substantiated, which allows to increase the efficiency of crushing soil clods and crop residues with toothed plates and teeth. Based on the principle of the multi-contact action of the teeth and toothed plates of the roller discs on the soil layer, the coefficient of the arrangement of the discs on the roller is equal to $0.22 \ldots 0.24$, as well as the number of toothed plates and teeth on the working surface of the roller disc, which is in the range of $6 \ldots 12$.

Laboratory tests have shown that an experimental tillage roller with loosening compacting discs reduces traction resistance by $12 \ldots 14 \%$, in comparison with the serial model 3RSR-6.

The study was carried out with the financial support of the Russian Foundation for Basic Research and the National Science Foundation of Bulgaria in the framework of a scientific application for project No. 20-58-18003.

\section{References}

1. Babitsky L F, Sobolevsky I V, Kuklin V A et al 2018 Theoretical backgrounds for the bionic substantiation of the parameters of the ringcutting soil-cultivating roller working bodies Agricultural science of the Euro-North-East 67(6) 121-127

2. Tong J, Qingzhu Z, Li et al 2015 Compaction Performance of Biomimetic Press Roller to Soil J. Bionic Eng 12(1) 152-159

3. Honglei J, Wenjun W, Wanpeng W et al 2018 Application of anti-adhesion structure based on earthworm motion characteristics Soil and Tillage Research 178 159-166

4. Turin E N 2020 Advantages and disadvantages of direct-seeded farming systems in the world (overview) Tavrichesky Bulletin of Agrarian Science 2 (22) 150-168

5. Soni P, Salokhe V M 2006 Influence of Dimensions of UHMW-PE Protuberances on Sliding Resistance and Normal Adhesion of Bangkok Clay Soil to Biomimetic Plates $J$. Bionic Eng 3(2) 63-71

6. Geoffrey A M 2009 Spontaneous otoacoustic emissions in lizards: A comparison of the skink-like lizard families Cordylidae and Gerrhosauridae Hearing Research 225(1-2) 58-66

7. Tong J, Ji W, Jia H et al 2015 Design and tests of biomimetic blades for soil-rototilling and stubble-breaking J. Bionic Eng 12(3) 495-503 doi:10.1016/s1672-6529(14)601402 .

8. Jia X 2006 Unsmooth cuticles of soil animals and theoretical analysis of their hydrophobicity and anti-soil-adhesion mechanism J. Colloid Interface Sci 295(2) 490-494

9. Babitskiy L F, Ismailov Y N, Ismailov R N Disc spur-toothed roller Patent RUS No 199408. 31.08.2020 Byul. No25 Available at: https://www1.fips.ru/ofpstorage/Doc/IZPM/RUNWU1/000/000/000/199/408/\%D0\%9F 
\%D0\%9C-00199408-00001/document.pdf

10. Tong J, Sun J, Chen D, Zhang S 2005 Geometrical features and wettability of dung beetles and potential biomimetic engineering applications in tillage implements Soil and Tillage Research 80(1-2) 1-12

11. Tong J, Zhang Q, Chang Y, Chen D, Dong W, Zhang L 2014 Reduction of soil adhesion and traction resistance of ridged bionic press roller Transactions of the Chinese Society for Agriculture Machinery 45 135-140

12. Barzegar M, Hashemi S J, Nazokdast N, Karimi R 2016 Evaluating the draft force and soil-tool adhesion of a UHMW-PE coated furrower Soil and Tillage Research 163 160167

13. Jia H L, Ma C L, Li G Y, Huang D Y, Liu Z C, 2007 Combined rototilling-stubblebreaking-planting machine Soil and Tillage Research 6 (1-2) 73-82

14. Honglei J, Wenjun W, Xiaofeng L, Jiaxin Z, Mingzhuo G, Jian Z, 2016 Effects of profiling elastic press roller on seedbed properties andsoybean emergence under double row ridge cultivation Soil and Tillage Research 162 34-40

15. Tong J, Moayad B Z, Ren L, Chen B, 2004 Biomimetics in soft terrain machine: A review International Agricultural Engineering Journal 13 71-86 